\title{
Experimental Investigation of the Effect of Using Porous Internal Sub-cooler on the Performance of Refrigeration System: R422A Case Study
}

\author{
Mohammad Tarawneh \\ Mechanical Engineering Department, Hashemite University, Zarqa, Jordan
}

Corresponding Author Email: mohammad.tarawneh@hu.edu.jo

https://doi.org/10.18280/ijht.370422

Received: 8 February 2019

Accepted: 9 December 2019

\section{Keywords:}

internal sub-cooler, performance, porosity, R422A, refrigerants, refrigeration, sub-cooling

\begin{abstract}
The effect of using porous sub-cooler on the performance of a refrigeration system using the refrigerant $\mathrm{R} 422 \mathrm{~A}$ as case study was experimentally investigated. The variations of refrigeration capacity, coefficient of performance, relative capacity index, power consumption per ton of refrigeration and pressure drop with degree of sub-cooling and internal sub-cooler porosity were studied. Results showed that the refrigeration capacity, coefficient of performance and relative capacity index can be improved by increasing degree of subcooling and decreasing the porosity of the internal sub-cooler with average percentages of increase of $38.5 \%, 48 \%$ and $58 \%$, respectively. The refrigerant R422A exhibited low power consumption per ton of refrigeration when using porous internal sub-cooler. Effects of internal sub-cooler effectiveness and pressure drop on the performance of the refrigeration system were also studied. An average percent decrease of about $9.5 \%$, of power consumption per ton of refrigeration was recorded by decreasing porosity from $43 \%$ to $40 \%$.
\end{abstract}

\section{INTRODUCTION}

Using porous materials in the flow passages of heat transfer fluids is one of the innovative techniques that can be used to enhance the heat transfer performance of thermal systems by improving the heat transfer rates and the heat transfer coefficients. Many of the heat transfer researchers in literature focused on different methods to improve the refrigeration capacities and coefficient of performance of refrigeration systems. Klein et al. [1] studied, theoretically, the effect of using liquid suction heat exchanger on the performance of refrigeration system. Gaffar et al. [2]. Examined, experimentally COP enhancement of domestic refrigerator by sub-cooling and super-heating using shell and tube type heat exchanger. Gustavo et al. [3]. Conducted experimental and numerical investigations on the effect of condenser subcooling on the performance of vapor compression systems. Bukola Bolaji et al. [4] performed a comparative analysis of the performance of hydrocarbon refrigerants with R22 in a sub-cooling heat exchanger refrigeration system. Joaquín Navarro et al. [5] conducted an experimental evaluation of internal heat exchanger influence on a vapor compression plant energy efficiency working with R22, R134a and R407C. Bolaji et al. [6] tested the influence of sub-cooling on the energy performance of two eco-friendly R22 alternative refrigerants. Prayudi et al. [7] investigated the effect of degree of sub-cooling on the performance of refrigeration with CFC, HFC and hydrocarbons refrigerant. Muhammad et al. [8] studied the effect of liquid suction heat exchanger sub-cooler on performance of a freezer using R404a as working fluid. Cecep et al. [9] studied the performance improvement using sub-cooling on freezer with R22 and R290 as refrigerants for various ambient temperatures. Prayudi et al. [10], performed heat transfer analysis on the effect of sub-cooling performance of vapor compression refrigeration system with cooling load variation. Boda Hadya [11] analyzed a vapor compression refrigeration system with sub- cooling and super-heating with three different refrigerants for air-conditioning applications. Tarawneh [12] conducted an experimental comparative study on the combined effect of using sub-cooling regenerator and porous evaporator on the performance of a refrigeration system using R422A and R22 as refrigerants. Sun et al. [13] studied the sub-cooled flow boiling with sintered porous coatings in small Channel. They conducted the experiments at atmospheric pressure for fully-deionized water as working fluid. Tarawneh [14] conducted an experimental performance study on the evaporation and pressure prop of low temperature refrigerant blends in porous media. Tarawneh concluded from this experimental performance study of the heat transfer behavior of different refrigerant blends that the refrigerant R422A has a heat transfer performance better than that of the refrigerant R404A in all of the experimental tests. Tarawneh et al. [15] investigated the effect of super-heating of different low-temperature refrigerant blends on the performance of a refrigeration system using porous evaporators. They concluded that, the coefficient of performance as well as the refrigeration capacity of the analysed refrigeration system, showed a reasonable increase when using porous evaporators. Cabelloa et al. [16] studied the energy influence of the use of internal heat exchanger with R-22 drop-in and long-term substitutes in refrigeration plants. Selbas et al. [17] conducted a thermo-economic optimization of sub-cooled, Tarawneh [18] derived a generalized correlation for the condensation and evaporation heat transfer coefficients of different refrigerants in porous horizontal tubes. Up to the on-hand references and up to the author knowledge, no one in literature studied the effect of using porous internal sub-coolers on the performance of a refrigeration system. This research comes to fill this gap in literature. In this experimental investigation a porous internal sub-cooler is used as a heat exchanger inserted 
between the condenser and the expansion valve in a vapor compression refrigeration system. The heat is exchanged between the worm liquid refrigerant coming from the condenser and the cold gaseous refrigerant coming from the evaporator, accordingly the liquid refrigerant is further subcooled before entering the expansion valve and the cold gas is super-heated before entering the compressor. This action will lead to actual increase in the refrigeration effect of the evaporator and save the compressor from probable moisture that can come from the evaporator. Using porous inserts in the low and high-pressure sides of the internal sub-cooler will increase the effectiveness of this heat exchanger, eventually, refrigeration capacity, coefficient of performance will increase and compressor power consumption per ton of refrigeration will decrease. Refrigerant R422A as one of proposed alternative low temperature refrigerant is considered as case study during this experimental work.

\section{EXPERIMENTAL WORK}

The schematic diagrams of the used experimental refrigeration system and the internal porous sub-cooler are shown in Figure 1 and Figure 2, respectively. The experimental work is conducted by using the setup shown in Figure 1. The refrigeration system used during the tests consists of condenser, hermetic type compressor of $0.75 \mathrm{hp}$ and [input power uncertainty of $\pm 1 \%$ ], evaporator, expansion valve in addition to internal porous sub-cooler fitted between the condenser and the expansion valve and filled with small metallic spheres as porous media with porosities of $(40 \%, 43 \%$ and $45 \%$ ). The selection of porosity values was based on random samples of small metallic spheres. Pressure transducers (uncertainty $\pm 1 \%$ of range) and k-type thermocouples with uncertainty of $\left( \pm 0.5^{\circ} \mathrm{C}\right)$ were used to measure the pressures and temperatures, respectively during the tests. The measured data is processed in Data Acquisition system (model SCXI 1000, manufactured by National Instruments Company) which is in turn connected to computer and printer. Thermophysical properties and composition of R422A as working refrigerant during the tests were selected from Bitzer Refrigerant Report [19]. The pressure drop-in lowpressure side of the internal porous sub-cooler is monitored. The effect of inserting a porous internal sub- cooler on the system performance is investigated when using R422A as working refrigerant with constant condensing and evaporating temperatures of $39^{\circ} \mathrm{C}$ and $-22^{\circ} \mathrm{C}$, respectively. The tests were repeated for empty and porous internal sub-cooler using different porosities and changing the degree of sub-cooling in the range of $\left(0^{\circ} \mathrm{C}-12^{\circ} \mathrm{C}\right)$. The degree of super-heat is kept constant at $6^{\circ} \mathrm{C}$ during the tests. The pressure- enthalpy diagram of the used refrigeration cycle with internal subcooler is plotted in Figure 3. Thermophysical properties of $\mathrm{R} 422 \mathrm{~A}$ are shown in Table 1 [13].

Table 1. Thermophysical properties of R422A

\begin{tabular}{|c|c|c|}
\hline 1 & Composition & $\begin{array}{c}\text { R-125/134a/600a } \\
(85.1 / 11.5 / 3.4)\end{array}$ \\
\hline 2 & Critical pressure (bar) & 37.5 bars \\
\hline 3 & $\begin{array}{c}\text { Critical Temperature } \\
\left({ }^{\circ} \mathrm{C}\right)\end{array}$ \\
\hline 4 & GWP & 71.8 \\
\hline 5 & ODP & 3144 \\
\hline
\end{tabular}

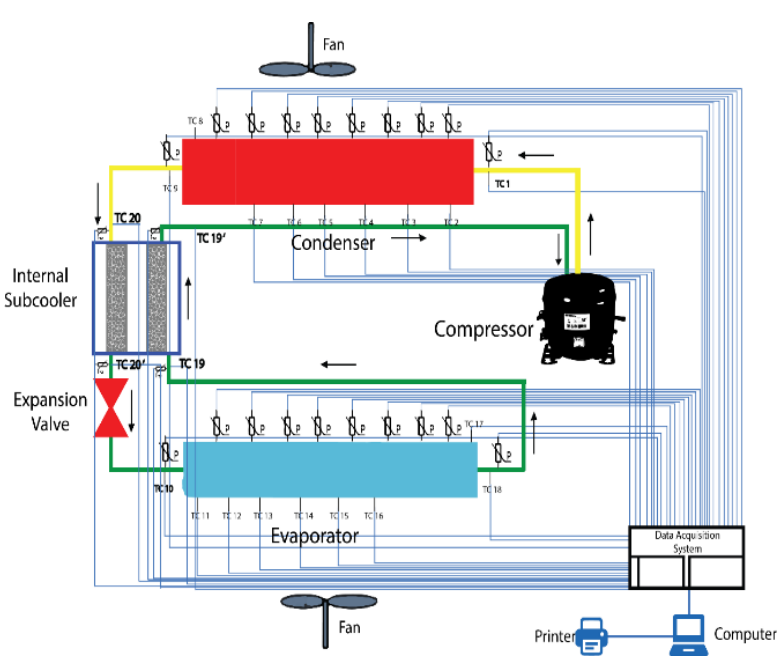

Figure 1. Schematic diagram of the used refrigeration system

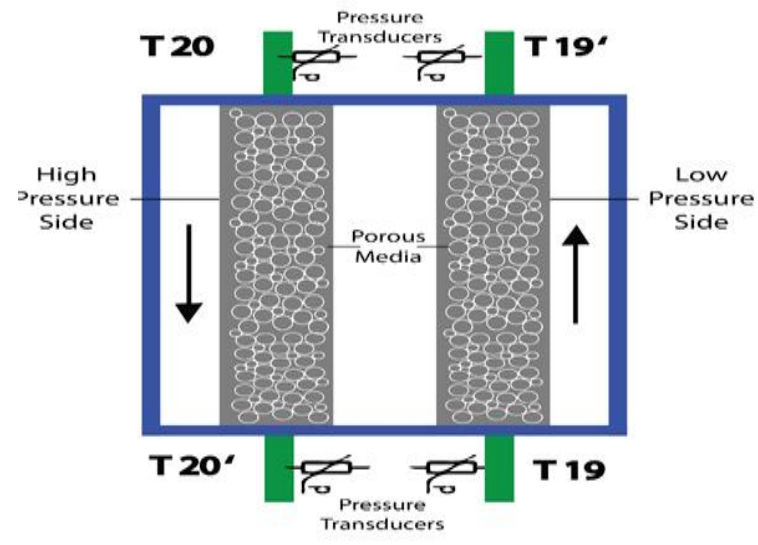

Figure 2. Internal porous sub-cooler

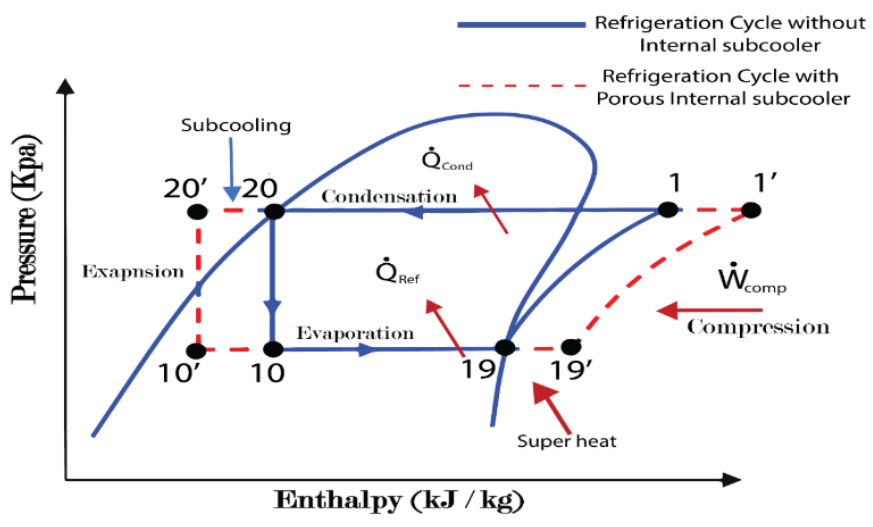

Figure 3. P-h diagram of the refrigeration system

\section{CYCLE PERFORMANCE ANALYSIS}

Different performance parameters were considered during this experimental study. Refrigeration capacity, coefficient of performance, relative capacity index, effectiveness of the internal sub-cooler, power consumption per ton of refrigeration and pressure drop, were calculated for different sub-cooling temperatures, different porosities of sub-cooler and constant condensing and evaporating temperatures. Using the P-h diagram in Figure 3, the refrigeration capacity can be calculated according to Eq. (1): 


$$
\dot{Q}_{\text {ref }}=\dot{m}_{R}\left(h_{19}-h_{10}^{\prime}\right)
$$

where, $\dot{m}_{R}$ is mass flow rate of $\mathrm{R} 422 \mathrm{~A}$ in $(\mathrm{kg} / \mathrm{s})$ and it can be calculated according to Eq. (2);

$$
\dot{m}_{R}=\dot{V} / v
$$

$V \cdot$ and $v$ are volumetric flow rate in $\left(\mathrm{m}^{3} / \mathrm{s}\right)$ and specific volume of the refrigerant $\mathrm{R} 422 \mathrm{~A}$ in $\left(\mathrm{m}^{3} / \mathrm{kg}\right)$, respectively. $h_{1^{\prime} 9}$ and $h_{10}^{\prime}$ are the refrigerant enthalpies at states $19^{\prime}$ and 10', respectively as shown in Figure 3. The coefficient of performance of the cycle can be found using Eq. (3):

$$
C O P=\frac{\dot{Q}_{r e f}}{\dot{W}_{\text {comp }}}
$$

where, $\dot{W}_{\text {comp }}$ is the compressor power in $(\mathrm{kW})$, which can be calculated according to Eq. (4):

$$
\dot{W}_{\text {comp }}=\dot{m}_{R}\left(h_{1}-h_{9}\right)
$$

h1' is the refrigerant enthalpy at the inlet of the compressor.

The effect of using internal sub-cooler on the cycle refrigeration capacity can detected by calculating the relative capacity index (RCI) according to Eq. (5) [1]:

$$
C O P=\frac{\dot{Q}_{\text {ref }}-\dot{Q}_{\text {refnsc }}}{\dot{Q}_{\text {refnsc }}} \times 100 \%
$$

$\dot{Q}_{\text {ref }}$ is the refrigeration capacity in $(\mathrm{Kw})$ with an internal sub-cooler.

$\dot{Q}_{\text {refnsc }}$ is the refrigeration capacity of the refrigeration system in $(\mathrm{Kw})$ without, using an internal sub-cooler but, using the same condensing and evaporating temperatures. Referring to Figure 2, the effectiveness of the internal sub-cooler (EISC) can be calculated according to Eq. (6):

$$
E I S C=\frac{T_{19}-T_{19}}{T_{20}-T_{19}} \times 100 \%
$$

where, T19' is the vapor temperature leaving, the internal subcooler, T19 is the vapor temperature entering the internal subcooler andT20 is the liquid temperature entering, the internal sub-cooler.

The compressor power consumption per ton of refrigeration PCPTR in $(\mathrm{kW} /$ ton of refrigeration) can be calculated according to Eq. (7):

$$
\text { PCPTR }=\frac{3.5 \dot{W}_{\text {comp }}}{\dot{Q}_{\text {ref }}}
$$

The pressure-drop $(\Delta \mathrm{P})$ in $(\mathrm{kPa})$ in the internal sub-cooler is detected as in Eq. (8):

$$
\Delta P=P_{19}-P_{19}
$$

where, $\mathrm{P} 19$ and $\mathrm{P} 19$ ' are the pressures in $(\mathrm{kPa})$ at the inlet and exit of the internal sub-cooler, respectively. The degree of subcooling $(\Delta \mathrm{T}(\mathrm{sub}))$ in ${ }^{\circ} \mathrm{C}$ can be found as in Eq. (9):

$$
\Delta T(s u b))=T_{20}-T_{20}^{\prime}
$$

T20 and T20' are temperatures of liquid at the inlet and exit of the internal sub-cooler, respectively.

\section{RESULTS AND DISCUSSIONS}

Different comparative performance parameters such as refrigeration capacity, COP, EISC, RCI, PCPTR and pressure drop through the ISC were studied during this experimental investigation. The performance of refrigeration system under study, when using empty and porous internal sub-cooler is examined. The tests were repeated without using internal subcooler. The variation of refrigeration capacity with degree of sub-cooling for different internal sub-cooler porosities is plotted in Figure 4. It can be noticed from this figure that the refrigeration capacity is increased by increasing the degree of sub-cooling and by decreasing the porosity of the internal subcooler with an average percentage increase of about $38.5 \%$. Figure 5 shows that the COP of the refrigeration system is enhanced by increasing the degree of sub-cooling and by decreasing the porosity of the internal porous sub-cooler with an average enhancement percentage increase of about $48 \%$.

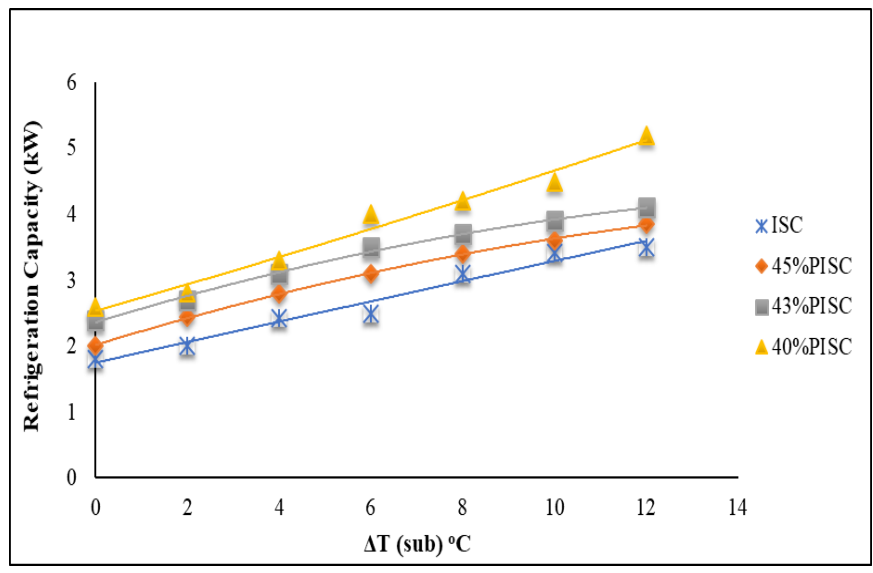

Figure 4. Variation of refrigeration capacity with $\Delta \mathrm{T}(\mathrm{sub}){ }^{\circ} \mathrm{C}$ for $\mathrm{Tc}=39^{\circ} \mathrm{C}$ and $\mathrm{Te}=-22^{\circ} \mathrm{C}$ for different porosities

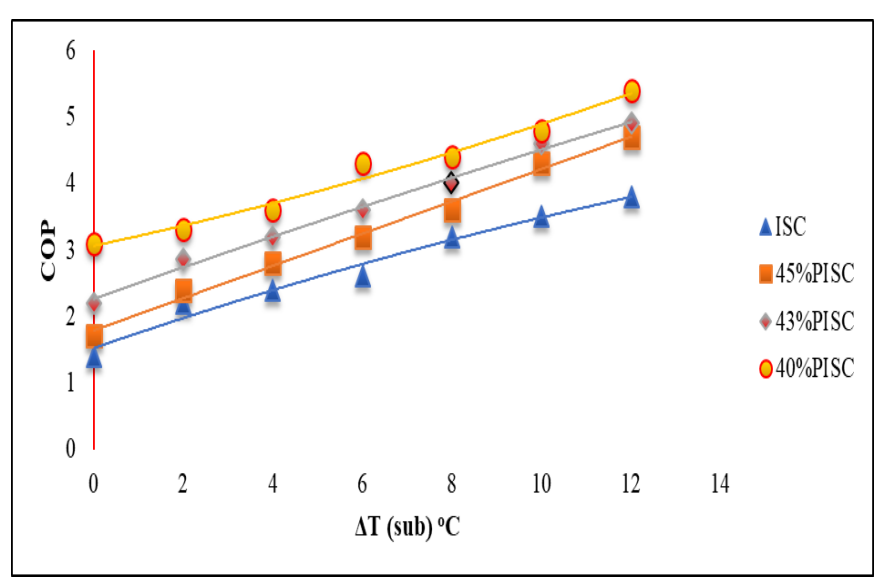

Figure 5. Variation of COP with $\Delta \mathrm{T}(\mathrm{sub}){ }^{\circ} \mathrm{C}$ for $\mathrm{Tc}=39^{\circ} \mathrm{C}$ and $\mathrm{Te}=-22^{\circ} \mathrm{C}$ for different porosities

The relative capacity index (RCI\%) represents the percentage change in the refrigeration capacity resulted from using the internal sub-cooler with different porosities in comparison with the situation at which no internal sub-cooler is used. The variation of RCI with degree of sub-cooling for different porosities is depicted in Figure 6. It can be concluded from this figure that, $\mathrm{RCI}$ is increased by increasing the degree of sub-cooling and by decreasing the porosity of the internal sub-cooler with an average percentage increase of about $58 \%$. 
The effectiveness of the internal sub-cooler is also increased by decreasing its porosity and increasing the degree of subcooling as it can be noticed in Figure 7. The average percentage increase of EISC reaches a value of about $80 \%$ as it can be concluded from Figure 7. Figure 8 represented the relationship between PCPTR and the change in porosity and the effectiveness of the ISC. It is concluded from this figure that, the power consumption in $(\mathrm{kW})$ per ton of refrigeration (PCPTR) is decreased by decreasing porosity and effectiveness of the internal sub-cooler with an average percentage decrease of about $9.5 \%$, when decreasing the porosity from $43 \%$ to $40 \%$.

Figure 9 shows the variation of the pressure drop in the lowpressure side of the IPSC with degree of subcooling for different porosities. It can be observed from this figure that the pressure drop is increased by increasing the degree of subcooling and by decreasing the porosity of the internal subcooler. The large increase in $\mathrm{COP}$ and the refrigeration capacity when using porous media compensated the increase in pressure drop. A performance comparative diagram of the studied refrigeration system with $\mathrm{R} 422 \mathrm{~A}$ as refrigerant is shown in Figure 10 for different degrees of sub-cooling and different porosities. It can be concluded from this figure that this candidate refrigerant exhibited high performances when increasing the degree of sub-cooling and increasing the effectiveness of the ISC by using porous inserts in the flow routes of the working refrigerant.

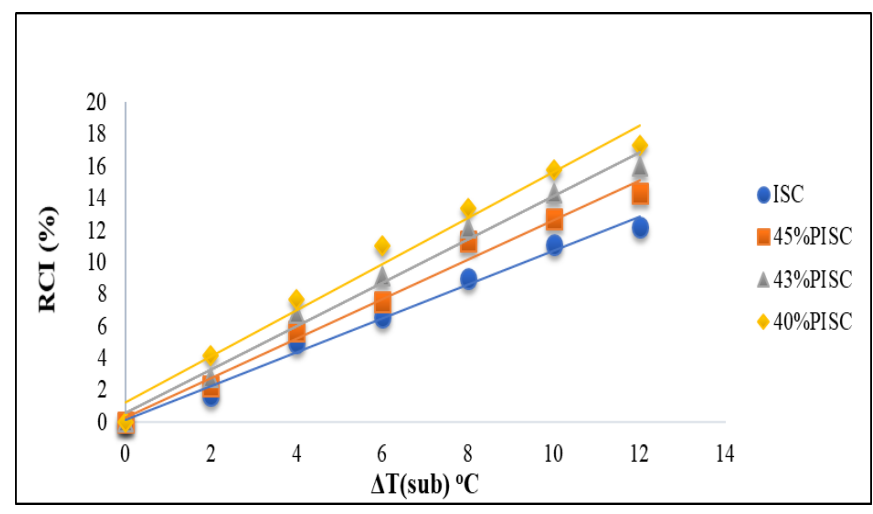

Figure 6. Variation of RCI (\%) with $\Delta \mathrm{T}(\mathrm{sub}){ }^{\circ} \mathrm{C}$ for $\mathrm{Tc}=39^{\circ} \mathrm{C}$ and $\mathrm{Te}=-22^{\circ} \mathrm{C}$ for different porosities

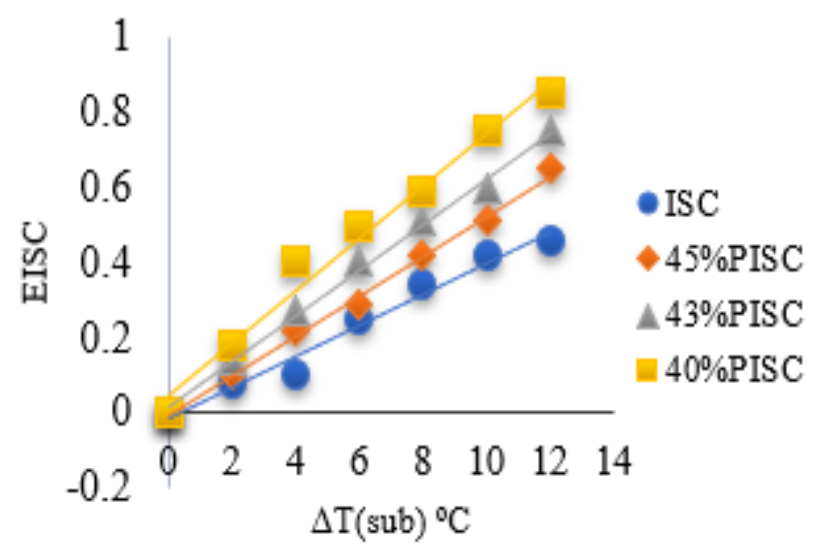

Figure 7. Variation of EISC with $\Delta \mathrm{T}(\mathrm{sub}){ }^{\circ} \mathrm{C}$ for $\mathrm{Tc}=39^{\circ} \mathrm{C}$ and $\mathrm{Te}=-22^{\circ} \mathrm{C}$ for different porosities

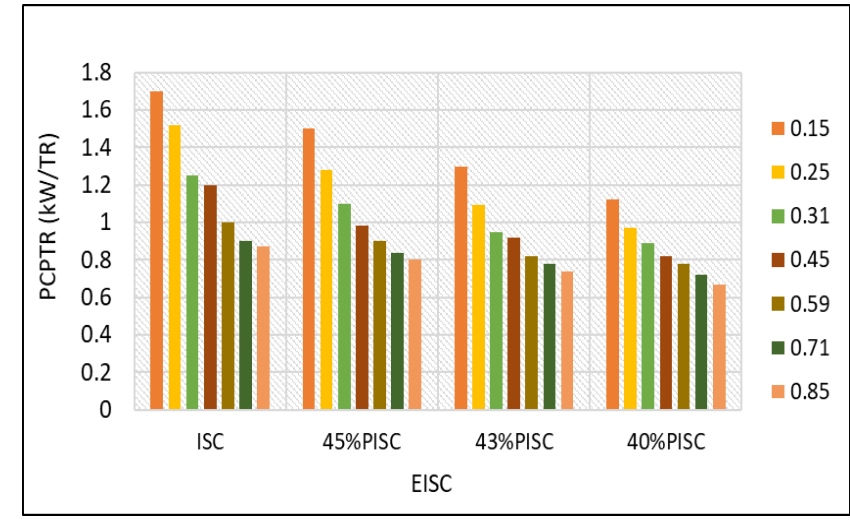

Figure 8. Variation of PCPTR with effectiveness of ISC for $\mathrm{Tc}=39^{\circ} \mathrm{C}$ and $\mathrm{Te}=-22^{\circ} \mathrm{C}$ for different porosities

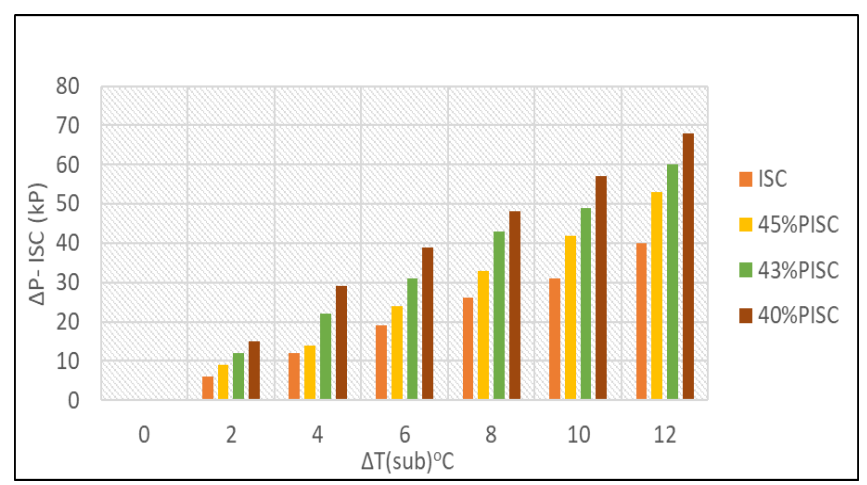

Figure 9. Variation of $\Delta \mathrm{P}$-ISC (kPa) with $\Delta \mathrm{T}(\mathrm{sub}){ }^{\circ} \mathrm{C}$ for $\mathrm{Tc}=39^{\circ} \mathrm{C}$ and $\mathrm{Te}=-22^{\circ} \mathrm{C}$ for different porosities

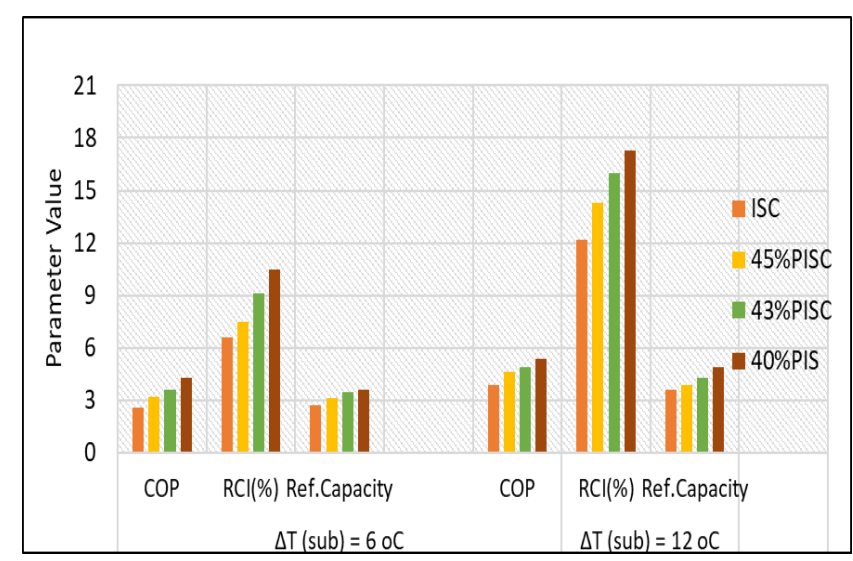

Figure 10. Performance comparative diagram of R422A for $\mathrm{Tc}=39^{\circ} \mathrm{C}$ and $\mathrm{Te}=-22^{\circ} \mathrm{C}$ with different porosities and different $\Delta \mathrm{T}$ (sub) ${ }^{\circ} \mathrm{C}$

\section{CONCLUSIONS}

It can be concluded from this experimental work, that using porous internal sub-cooler is one of the innovative techniques that can enhance the performance of refrigeration systems working on low temperature refrigerant blends. The refrigeration capacity of $\mathrm{R} 422 \mathrm{~A}$ as well as the COP and RCI were improved when using porous internal sub-cooler. It was noticed that, the coefficient of performance (COP)of the refrigeration system can be increased by decreasing the porosity of the internal sub-cooler. Low power consumption per ton of refrigeration (PCTR) was recorded at low porosities 
of the internal sub-cooler. Low power consumption was recorded at high sub-cooler effectiveness. As degree of subcooling increases, the sub-cooler effectiveness increases with an average percentage increase of about $80 \%$. It can be concluded also, that the installation of internal sub-cooler prevents the presence of vapor in the line entering the expansion valve and prevents also the presence of liquid refrigerants in the lines entering the compressor. High values of pressure drop in the porous sub-cooler were compensated by the valuable increase in $\mathrm{COP}$ and valuable decrease in power consumption. It can be concluded from this experimental research that, the power consumption per ton of refrigeration (PCPTR) can be decreased by increasing the degree of sub-cooling and increasing the porous internal subcooler effectiveness.

\section{UNCERTAINITY STUDY}

The uncertainties in the different experimental measured and calculated performance parameters were found by using an uncertainty study and the results are tabulated in Table 2 .

Table 2. Uncertainty study results

\begin{tabular}{|c|c|}
\hline Experimental parameter & Uncertainty \\
\hline Pressure reading $(\mathrm{kPa})$ & $\pm 1 \%$ of range \\
\hline Temperature reading $\left({ }^{\circ} \mathrm{C}\right)$ & $\pm 0.5^{\circ} \mathrm{C}$ \\
\hline $\begin{array}{c}\text { Volumetric Flowrate reading } \\
\text { (liter/minute) }\end{array}$ & \pm 0.09 liter/min \\
\hline Refrigeration capacity $(\mathrm{kW})$ & $\pm 0.1 \mathrm{~kW}$ \\
\hline Compressor power $((\mathrm{kW})$ & $\pm 1 \%$ \\
\hline COP & \pm 0.15 \\
\hline RCI \% & $\pm 1.2 \%$ \\
\hline PCPTR $(\mathrm{kW} /$ ton $)$ & $\pm 0.19(\mathrm{~kW} /$ ton $)$ \\
\hline
\end{tabular}

\section{ACKNOWLEDGEMENTS}

This experimental work is supported technically by Engineering Geniuses Company (www.egeniuses.net)Jordan/Amman.

\section{REFERENCES}

[1] Klein, S.A., Reindl, D.T., Brownell, K. (2000). Refrigeration system performance using liquid-suction heat exchangers. International Journal of Refrigeration, 23(8): $\quad$ 588-596. https://doi.org/10.1016/S01407007(00)00008-6

[2] Momin, G.G., Tupe, S.B., Parate, S.A. (2016). COP enhancement of domestic refrigerator by sub cooling and superheating using shell \&tube type heat exchanger. International Journal of Engineering Research and Advanced Technology (IJERAT), 2(5): 1-10.

[3] Pottker, G., Hrnjak, P. (2012). Effect of condenser subcooling of the performance of vapor compression systems: Experimental and numerical investigation. International Refrigeration and Air Conditioning Conference at Purdue, pp. 16-19. http://docs.lib.purdue.edu/iracc/1328/

[4] Bolaji, B.O.,Huan, Z.J. (2012). Comparative analysis of the performance of hydrocarbon refrigerants with R22 in a sub-cooling heat exchanger refrigeration system.
Journal of Power and Energy, 226(7): 882-891. https://doi.org/10.1177\%2F0957650912454829

[5] Navarro-Esbrí, J., Cabello, R., Torrella, E. (2005). Experimental evaluation of the internal heat exchanger influence on a vapor compression plant energy efficiency working with R22, R134a and R407C. Energy, 30(5): 621-636. https://doi.org/10.1016/j.energy.2004.05.019

[6] Bolaji, B.O. (2015) Influence of sub-cooling on the energy performance of two eco-friendly R22 alternative refrigerants. Journal of Science and Technology, 34(2): 73-83. https://doi.org/10.4314/just.v34i2.9

[7] Suparmin, P., Antono, V., Nurhasanah, R.(2017). Effect degree of temperature subcooling on the performance of refrigeration with $\mathrm{CFC}$, $\mathrm{HFC}$ and hydrocarbons refrigerant. MATEC Web of Conferences, 101: 03002. https://doi.org/10.1051/matecconf/201710103002

[8] Nuriyadi, M., Sumeru, S., Nasutionb, H. (2015). The effect of liquid suction heat exchanger sub-cooler on performance of a freezer using R404a as working fluid. Journal of Technology, 76(11): 57-61. https://doi.org/10.11113/jt.v76.5914

[9] Sunardi, C., Martin, L., Sumeru, K., Nasution, H. (2016). Performance improvement using subcooling on freezer with R22 and R290 as refrigerant for various ambient temperatures. ARPN Journal of Engineering and Applied Sciences, 11(2): 906-911.

[10] Prayudi, Nurhasanah, B. (2016). Analysis of effect of sub cooling performance of vapor compression refrigeration system with cooling load variation. ARBAN Journal of Engineering and Applied Sciences, 11(2).

[11] Hadya, B. (2016). Analysis of vapor compression refrigeration system with sub- cooling and super heating with three different refrigerants for air-conditioning applications. International Journal of Engineering Sciences \& Research Technology. 5(11). https://doi.org/10.5281/zenodo.164904

[12] Tarawneh, M. (2019). Combined effect of using subcooling regenerator and porous evaporator on the performance of refrigeration system. International Journal of Innovative Technology and Exploring Engineering (IJITEE), 8(8): 1262-1268.

[13] Sun, Y., Zhang, L., Xu, H., Ji, D.M. (2010). Subcooled flow boiling with sintered porous coatings in small channel. 14th International Heat Transfer Conference, Washington, DC, USA. pp. 317-326. https://doi.org/10.1115/IHTC14-22565

[14] Tarawneh, M. (2019). Performance study on the evaporation and pressure drop of low temperature refrigerant blends in porous media. Heat Transfer Asian Research, $\quad 48(4)$ : 1381-1398. https://doi.org/10.1002/htj.21437

[15] Tarawneh, M., Jawarneh, A.M., Tlilan, H., Ababneh, A., Al-Migdady, A. (2019). Investigation of the effect of superheating on the performance of a refrigeration system using low temperature different refrigerant blends in porous media. Heat Transfer Asian Research, 48(6): 2216-2236. https://doi.org/10.1002/htj.21481

[16] Cabelloa, R., Torrellab, E., Llopisa, R., Sáncheza, D., Larumbeb, J.A. (2013). Energy influence of the IHX with R22 drop-in and long-term substitutes in refrigeration plants. Appl Therm Eng., 50(1): 260-267. https://doi.org/10.1016/j.applthermaleng.2012.06.008

[17] Selbas, R., Kızılkan, O., Sencan, A. (2006). Thermoeconomic optimization of subcooled and 
superheated vapor compression refrigeration cycle. Energy, 31(12): 2108-2128. https://doi.org/10.1016/j.energy.2005.10.015

[18] Tarawneh, M. (2015). Generalized correlation for the condensation and evaporation heat transfer coefficients of Propane (R290), Butane (R600), R134a and R407c in porous horizontal tubes: Experimental investigation. ICMMME 2015, International Conference on Mechanical, Materials and Mechatronics Engineering that was held in Madrid, Spain.

[19] Refrigerant Report. Bitzer International15th Edition, 71065 Sindelfingen, Germany.

\section{NOMENCLATURE}

\section{$\mathrm{C}$}

$\mathrm{CFC}$

COP

EISC

\section{$\mathrm{H}$}

HFC

ISC

$\mathrm{P}$

PCPTR

\section{Centigrade}

Chlorofluorocarbon

dimensionless coefficient of performance dimensionless effectiveness of the internal sub-cooler enthalpy $(\mathrm{kJ} / \mathrm{kg})$

Hydrofluorocarbon Internal sub-cooler Pressure $(\mathrm{kPa})$

Power consumption per ton of refrigeration (kW/TR)
PISC Porous Internal Sub-cooler

$\dot{Q}_{\text {refnsc }}$

Refrigeration capacity without internal subcooler

R Refrigerant

RCI Refrigeration capacity index (\%)

Ref. Refrigeration capacity (kW)

Capacity

Tc

Condensing temperature in $\left({ }^{\circ} \mathrm{C}\right)$

$\mathrm{Te}$

Evaporation Temperature in $\left({ }^{\circ} \mathrm{C}\right)$

W Watt

\section{Greek symbols}

$\Delta \mathrm{T}(\mathrm{sub}){ }^{\circ} \mathrm{C} \quad$ degree of sub-cooling in degree centigrade $\triangle \mathrm{PISC}$ pressure drop in the internal sub-cooler $(\mathrm{kPa})$

\section{Subscripts}

$\begin{array}{ll}\text { C } & \text { Condensation } \\ \text { E } & \text { Evaporation } \\ \text { sub } & \text { Subcooling }\end{array}$

\section{Superscripts}

o

degree 